\title{
Correlation of Forearm Circumference and Hand Length with Grip Strength in Healthy Young Adults
}

\author{
Seethamma KM${ }^{1}$, Joseph Oliver Raj ${ }^{2 *}$, Nithin Prakash ${ }^{3}$ and Kshama Shetty ${ }^{4}$ \\ ${ }^{1}$ Post Graduate student, Alva's college of Physiotherapy, Dakshin Karnataka, India \\ ${ }^{2}$ Principal, Alva's college of Physiotherapy, Dakshin Karnataka, India \\ ${ }^{3}$ Lecturer, Alva's college of Physiotherapy, Dakshin Karnataka, India \\ ${ }^{4}$ Associate Professor, Alva's college of Physiotherapy, Dakshin Karnataka, India \\ *Corresponding Author: Joseph Oliver Raj, Alva's College of Physiotherapy, Dakshin Karnataka, India.
}

Received: August 14, 2019; Published: September 12, 2019

DOI: 10.31080/ASOR.2019.02.0100

\begin{abstract}
Introduction: Grip strength measurement is used as an indicator for many hand and forearm related orthopaedic injuries as well as in neurological assessment.

Aim: To find whether anthropometric measurements like hand length and forearm circumference have influence on hand grip strength of young healthy adults.

Material and Methods: 198 healthy young adults were used for the study for data collection. Grip strength of both hands were done with hand held dynamometer. Anthropometric measurements of hand length and forearm circumference was done using measuring tape.

Results and Discussion: The result showed that there is statistical significance between hand grip strength and both anthropometric measurements, that is, hand length and forearm circumference.

Conclusions: Hand grip strength has direct correlation with the anthropometric measurement of hand length and forearm circumference. Hence hand grip strength is associated with hand length and forearm circumference irrespective of age and gender.

Keywords: Grip Strength; Forearm Circumference; Dynamometer; Hand Length
\end{abstract}

\section{Introduction}

Human hand is noted for its complex structure and devoted motor function of manipulation and sensory functions of relaying various deep and superficial sensations to the brain [1]. The highly elaborated nervous control, sensitivity of the fingers and the ability to perform firm grip contributes to the sensory and motor efficacies of hand complex. Clinically the overall physical strength and health are done by assessing the hand grip strength. The importance of hand strength has been identified in predicting disability in musculoskeletal diseases and bone mineral density as well as in likelihood of falls and fractures in osteoporosis [2]. The dynamometer has been found to give the most accurate and acceptable measures of grip strength by quantifying the amount of static force with which the hand can squeeze the dynamometer and is commonly measured in Kilograms or pounds [2].

The information regarding human sizes is essential in designing various facilities and an anthropometric measurement of hand is very important for designing of various objects dealing with human hands. There has been a positive correlation between grip strength

Citation: Joseph Oliver Raj., et al. "Correlation of Forearm Circumference and Hand Length with Grip Strength in Healthy Young Adults". Acta Scientific Orthopaedics 2.10 (2019): 10-15. 
and anthropometrics including hand anthropometric measurements in healthy Indian men [1]. The force applied by the hand to pull on or suspend from objects is called the grip strength, a specific part of hand strength [3]. Objects with an optimum size of around 1 - 3 inches diameter permit the hand to wrap around objects, which are usually cylindrical in nature.

Grip strength is often used in physiotherapy as a specific type of hand strength, purpose of testing, including to diagnose disease, evaluate and compare treatment, to document progression of muscle strength and provide feedback during rehabilitation process as a measure indicating the level of hand function, and also be able to predict a decline in function in old age.

Many factors which includes fatigue, hand dominance, time of day, state of nutrition, pain, cooperation of patients, presence of amputation, restriction of movements, sensory loss are affected by hand grip [4].

Types of grips

Hand grips are divided into the following:

Power grip: There are 3 types:

a) Cylindrical: All fingers are flexed around the object which is usually at a right angle to the forearm and the thumb around the object held.

b) Spherical: All the fingers and the thumb are adducted around the object. Fingers spread apart, palm often not involved.

c) Hook grip: Involve second through fifth finger flexed around an object in a hook like manner. Usually thumb is not involved.

\section{Precision grip}

- $\quad$ Tends to hold the object between the tips of the finger and thumb

- Thumb is abducted

- Used in the fine movements and accuracy

- $\quad$ Objects are small or fragile

- No involvement of palm and proximal joints

There are 4 types

1. Pad to pad (pinch)

2. Tip to tip (pincer grip)

3. Lateral prehension

4. Lumbrical grip

\section{Grip strength measurement}

Can be measured by using hand dynamometer. Normal value for adult male / female in $\mathrm{kg}$ [6]

\begin{tabular}{|l|c|c|}
\hline & Male & Female \\
\hline Excellent & $>64$ & $>38$ \\
\hline Very good & $56-64$ & $34-38$ \\
\hline Above average & $52-55$ & $30-33$ \\
\hline Average & $48-51$ & $26-29$ \\
\hline Below average & $44-47$ & $23-25$ \\
\hline Poor & $40-43$ & $20-22$ \\
\hline Very poor & $<40$ & $<20$ \\
\hline
\end{tabular}

Table A:

\section{Methodology and Materials}

The subjects for this observational study design were selected by simple random sampling.

The study sample size is 198 subjects and study was done for a duration of three months.

Inclusion riteria

- $\quad$ Apparently healthy individuals both males and females of age between 18 to 24 years

- Willingness to participate

Exclusion criteria

- $\quad$ History of any systemic disorders

- $\quad$ History of any fracture, hand or nerve injury in upper limb

- $\quad$ Pain in the upper extremity

- $\quad$ Post - surgical condition and neurological pathology.

\section{Materials}

- $\quad$ Consent form

- $\quad$ Recording sheets

- Hydraulic hand dynamometer

- Inch tape

- Weighing machine

- Stadiometer

Procedure

After clearance from institutions ethical clearance committee, a prior informed consent was obtained from the participants and those who fulfilled the selection criteria were selected among those individuals. Simple random sampling method was used for selection. 


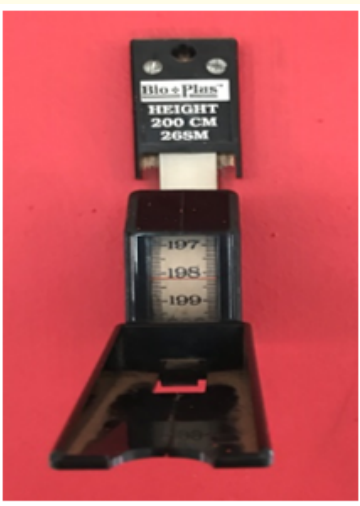

Figure 1: Stadiometer.

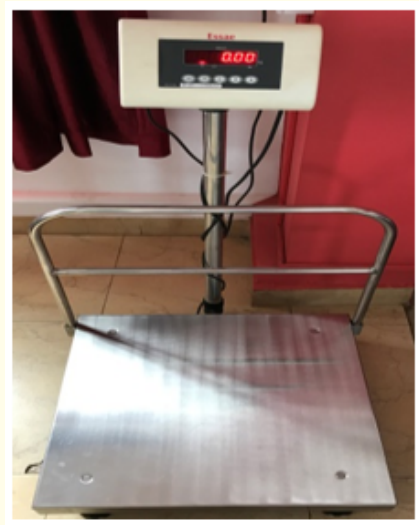

Figure 2: Electronic Weighing scale.

\section{Hand held dynamometer [5]}

Record the participant's hand dominance. Participants were made to be seated in a comfortable chair with back support and fixed arm rest. Participants were informed to keep their forearm on the arms of chair and feet flat on the ground.

When squeezing the dynamometer, participants feet should not raise from the ground and the thumb should be facing upwards with the hand placed at edge of the chair's arm.

Handle should be grasped from one side with thumb and other side with fingers.

Position of red needle on dial should be at " 0 " when starting the procedure.
Handle should be squeezed tightly till needle stops.

Readings of measurements are taken in $\mathrm{kg}$ which is seen in outer dial and total of three readings are taken alternatively for both hands.

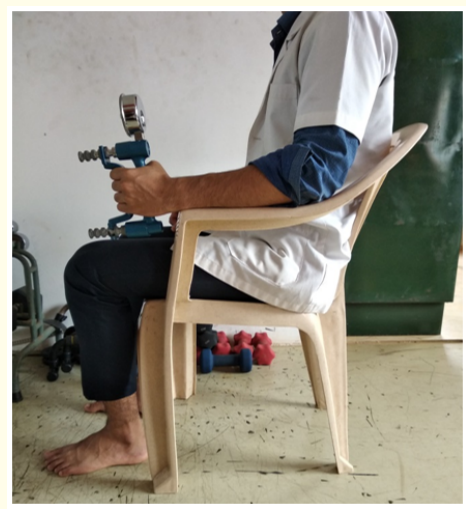

Figure 3: Position of patient with hand held dynamometer.

\section{Hand dimension measurements}

The measurement techniques of hand dimensions were carried out by using a standard measurement tape as proposed for both hands [7]. Largest and thinnest parts of forearm were taken for forearm and wrist circumference.

Perimeter of the middle part of the hand was considered for palm length. For palm length, distance from the distal wrist crease up to the base of the middle finger and lastly for the hand length, the distal wrist crease to the tip of the middle finger was considered for measurement.

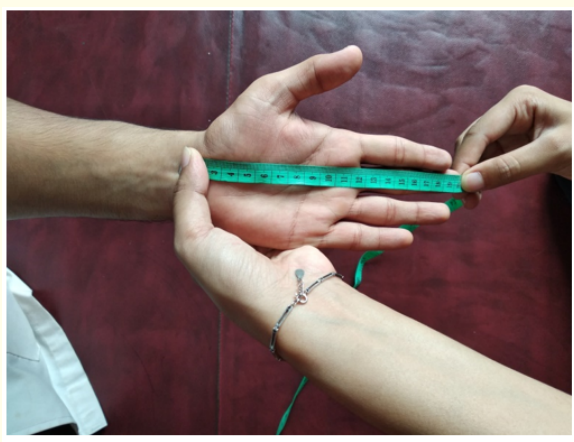

Figure 4: Hand dimensions measurement. 
13

Forearm circumference measurements

With arm extended, measurement of forearm girth was taken where maximum muscle bulk was present in forearm with 3 readings [7].

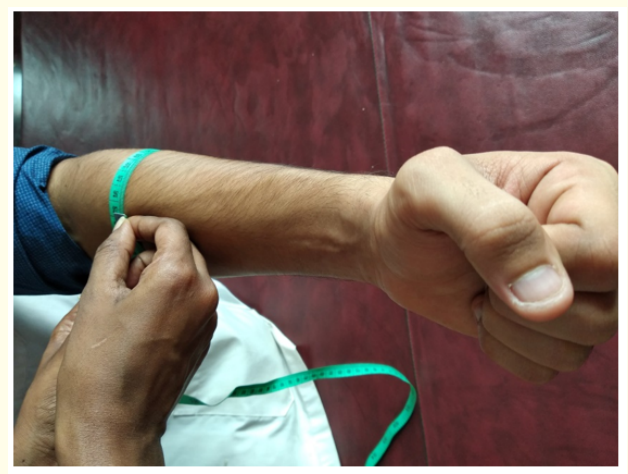

Figure 5: Forearm circumference measurement.

\section{Statistical analysis}

Statistical analysis was done using SPSS 20 and T test was used for statistical measurement for grip strength and forearm circumference and hand length. Statistical method used between grip strength and BMI was ANOVA.

T-Test

\begin{tabular}{|c|l|c|c|c|c|}
\hline \multicolumn{2}{|c|}{} & Mean & N & $\begin{array}{c}\text { Std. } \\
\text { Deviation }\end{array}$ & $\begin{array}{c}\text { Std. Error } \\
\text { Mean }\end{array}$ \\
\hline \multirow{2}{*}{ Pair 1 } & $\begin{array}{l}\text { Forearm } \\
\text { Circumference } \\
\text { Left }\end{array}$ & 25.49 & 43 & 4.026 & 0.614 \\
\cline { 2 - 6 } & $\begin{array}{l}\text { Grip Strength } \\
\text { Left }\end{array}$ & 24.21 & 43 & 10.188 & 1.554 \\
\hline
\end{tabular}

Table 1: Paired Samples Statistics.

\begin{tabular}{|c|l|c|c|c|}
\hline \multicolumn{2}{|l|}{} & N & Correlation & Sig. \\
\hline Pair 1 & $\begin{array}{l}\text { Forearm circumference left } \\
\text { and Grip strength left }\end{array}$ & 43 & 0.035 & 0.826 \\
\hline
\end{tabular}

Table 2: Paired Samples Correlations.

\begin{tabular}{|l|l|c|c|c|c|}
\hline \multicolumn{2}{|c|}{} & Mean & N & $\begin{array}{c}\text { Std. } \\
\text { Deviation }\end{array}$ & $\begin{array}{c}\text { Std. Error } \\
\text { Mean }\end{array}$ \\
\hline Pair 1 & $\begin{array}{l}\text { Hand length } \\
\text { (Cm) R }\end{array}$ & 19.03 & 188 & 1.825 & 0.133 \\
\cline { 2 - 6 } & $\begin{array}{l}\text { Grip strength } \\
\text { right }\end{array}$ & 25.21 & 188 & 9.975 & 0.727 \\
\hline
\end{tabular}

Table 3: Paired Samples Statistics.

\begin{tabular}{|l|l|c|c|c|}
\hline \multicolumn{2}{|l|}{} & N & Correlation & Sig. \\
\hline Pair 1 & $\begin{array}{l}\text { Hand length }(\mathrm{Cm}) \text { R and } \\
\text { grip strength right }\end{array}$ & 188 & 0.366 & 0.000 \\
\hline
\end{tabular}

Table 4: Paired Samples Correlations.

\begin{tabular}{|l|c|c|c|c|c|}
\hline ANOVA & $\begin{array}{c}\text { Sum of } \\
\text { Squares }\end{array}$ & Df & $\begin{array}{c}\text { Mean } \\
\text { Square }\end{array}$ & F & Sig. \\
\hline Between Groups & 614.613 & 38 & 16.174 & 1.175 & 0.246 \\
\hline Within Groups & 2050.595 & 149 & 13.762 & & \\
\hline Total & 2665.207 & 187 & & & \\
\hline
\end{tabular}

Table 5: Grip strength left- BMI.

\begin{tabular}{|l|c|c|c|c|c|}
\hline ANOVA & $\begin{array}{c}\text { Sum of } \\
\text { Squares }\end{array}$ & Df & $\begin{array}{c}\text { Mean } \\
\text { Square }\end{array}$ & F & Sig. \\
\hline Between Groups & 846.142 & 39 & 21.696 & 1.765 & 0.008 \\
\hline Within Groups & 1819.065 & 148 & 12.291 & & \\
\hline Total & 2665.207 & 187 & & & \\
\hline
\end{tabular}

Table 6: Grip strength right- BMI.

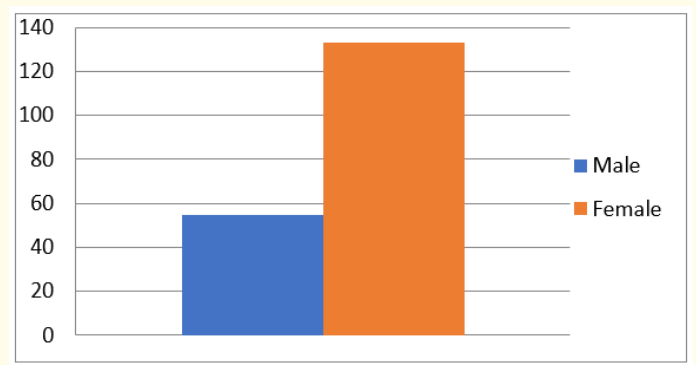

Figure 6: Graph representing distribution of male and female participants. 


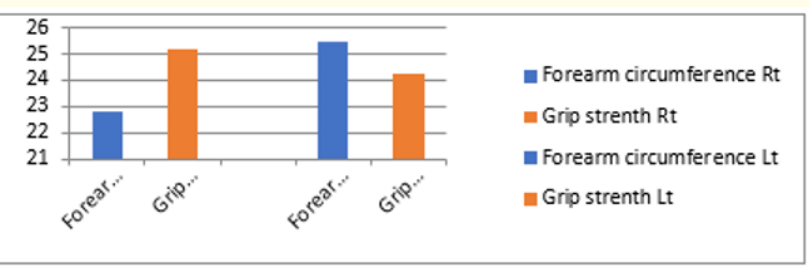

Figure 7: Graphical representation of forearm circumference and grip strength.

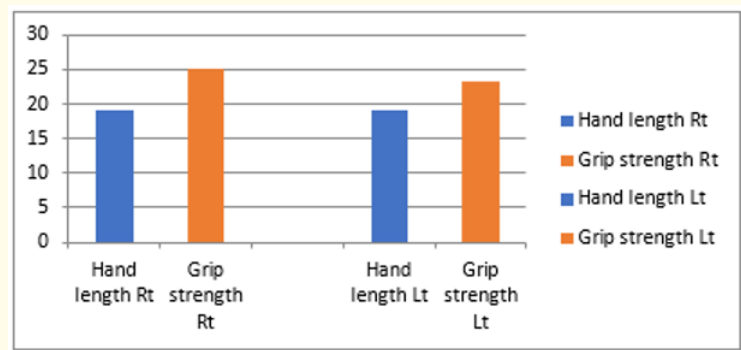

Figure 8: Graphical representation of hand length and grip strength.

\section{Results and Discussion}

From the results of this study, it is evident that the correlation between forearm circumference and hand grip strength (both right and left) is statistically significant which is similar to the studies by other prominent authors in the past. There is statistically significant correlation between hand length and hand grip strength on both right and left sides.

Physical strength of an individual is measured by assessing the effective muscle contraction. Muscle contraction depends on cross sectional area of muscle and its intensity of recruitment. Individuals with more type II fibres have greater physical endurance. The strength capability analysis is done by asking the individual to perform a particular task like pushing or lifting an object.

The observations are compared with capabilities of a section of population. The quantification of hand grip strength can be done by measurement of static force that the hand exerts on a dynamometer [1].
The grip strength depends on the synergistic forearm flexor and extensor muscle action and its interplay [8]. Movement of the forearm and hand are mostly performed by forearm muscles.

The flexor muscles of the forearm and hand create grip strength while performing gripping activities whereas the stabilization of the wrist is carried by the extensors of the forearm [9].

There was statistical analysis between all anthropometric data and grip strength in both males and females that showed a positive correlation. This finding was similar to the report from study which showed strong correlation between hand circumference and grip strength [10]. Therefore, muscle strength is impaired in obese people due to the sedentary lifestyle and low physical fitness [11]. Also, there was significant correlation with forearm circumference and hand grip strength, the higher the forearm diameter the higher is the grip strength [12].

The fibber diameter of the flexor digitorum sublimes on the flexion contractile ability of the hand influences and explains the correlation between forearm girth and handgrip strength. Consequently, the forearm circumference and hand length can be used as a medium of hand grip strength among young adults [12-27].

\section{Conclusion}

Hand grip strength has direct correlation with the anthropometric measurement of hand length and forearm circumference. Hence hand grip strength is associated with hand length and forearm circumference irrespective of age and gender.

\section{Conflict of Interest}

No conflict of interest in any matter existed among the corresponding author and other authors.

\section{Bibliography}

1. Shah UN., et al. "The association between hand grip strength and hand dimensions in healthy Indian females". International Journal of Current Research and Review 4.2 (2012).

2. Angst F., et al. "Prediction of grip and key pinch strength in 978 healthy subjects". BMC Musculoskeletal Disorders 11 (2010): 94.

3. Babu YK and Saraswathi P. "A study on influence of wrist joint position grip strength in normal adult male individuals". Internal Journal of Drug Development and Research (2014). 
4. Adedoyin RA., et al. "References values for hand grip strength among healthy adults in Nigeria”. Hong Kong Physiotherapy Journal 27.1 (2009): 21-29.

5. Mathiowetz V. "Comparison of Rolyan and Jamar dynamometers for measuring grip strength". Occupational Therapy Internationa 9.3 (2002): 201-209.

6. Massey-Westrop N., et al. "Measuring grip strength in normal adult: reference ranges and a comparison of electronic and hydraulic instruments". Journal of Hand Surgery American 29.3 (2004): 514-519.

7. Mohan V., et al. "Forearm circumference and hand length predicts maximal hand grip strength among Malaysian population". Middle East Journal of Scientific Research 21.4 (2014): 634-639.

8. Ahmed T. "The effect of upper extremity ftigue on grip strength and passing accuracy in junior basketball players". Journal of Human kinetics 37 (2013): 71-79.

9. Butefisch C., et al. "Repetitive training of isolated movements improves the outcome of motor rehabilitation of the centrally paretic hand". Journal of the Neurological Sciences 130.1 (1995): 59-68.

10. Li K., et al. "Predicting maximal grip strength using hand circumference". Manual Therapy 15.6 (2010): 579-585.

11. Rolland Y., et al. "Muscle strength in obese elderly women: effect of recreational physical activity in cross-sectional study". American Journal of Clinical Nutrition 79.4 (2004): 552-557.

12. Okaraogur U., et al. "Association of grip strength with anthropometric measures: Height, forearm diameter and middle finger length in young adults". Polish Annals of Medicine 24.2 (2017): 153-157.

13. Ling CH., et al. "Handgrip strength and mortality in the oldest old population: the Leiden 85-plus study". Canadian Medical Association Journal 182.5 (2010):429-435.

14. Foo LH., et al. "Influence of body composition, muscle strength, diet and physical activity on total body and forearm bone mass in Chinese adolescent girls". British Journal of Nutrition 98.6 (2007):1281-1287.

15. Samson MM., et al. "Relationships between physical performance measures, age, height and body weight in healthy adults". Age and Ageing 29.3 (2000): 235-242.

16. Onder G., et al. "Change in physical performance over time in older women: the women's Health and Aging Study". The journals of gerontology. Series A, Biological sciences and medical sciences 57.5 (2002): M289-M293.
17. Chilima DM and Ismail SJ. "Nutrition and hand grip strength of older adults in rural Malawi". Public Health Nutrition 4.1 (2001):11-17.

18. Pieterse S., et al. "The association between nutritional status and hand grip strength in older Rwandan refugees". European Journal of Clinical Nutrition 56.10 (2002): 933-939.

19. Abbott JH CE., et al. "The initial effects of an elbow mobilization with movement technique on grip strength in subjects with lateral epicondylalgia". Manual Therapy 6.3 (2001): 163-169.

20. Mostert, R., et al. "Tissue depletion and health related quality of life in patients with chronic obstructive pulmonary disease". Respiratory Medicine 94.9 (2000): 859-867.

21. Stalenhoef PA., et al. "A risk model for the prediction of recurrent falls in community dwelling elderly: a prospective cohort study". Journal of Clinical Epidemiology 55.11 (2002): 1088-1094.

22. Ali NA., et al. "Midwest Critical Care Consortium Acquired weakness, handgrip strength and mortality in critically ill patients". American Journal of Respiratory and Critical Care Medicine 178.3 (2008): 261-268.

23. Norman K., et al. "Hand grip strength: outcome predictor and marker of nutritional status". Clinical Nutrition 30.2 (2011): 135-142.

24. Wind AE., et al. "Is grip strength a predictor for total muscle strength in healthy children, adolescents and young adults?". European Journal of Pediatrics 169.3 (2010):281-287.

25. Sultan P., et al. "Preoperative muscle weakness as defined by handgrip strength and postoperative outcomes: a systematic review". BMC Anesthesiol 169 (2012): 281-287.

26. Kamarul T., et al. "Hand grip strength in the adult Malaysian population". Journal of Orthopaedic Surgery (Hong Kong) 14.2 (2006): 172-177.

27. SmidtN., et al. "Interobserver Reproducibility of the Assessment of Severity of Complaints, Grip Strength, and Pressure Pain Threshold in Patients with Lateral Epicondylitis". Archives of Physical Medicine and Rehabilitation 83.8 (2002):1145-1150.

\section{Volume 2 Issue 10 October 2019 (C) All rights are reserved by Joseph Oliver Raj., et al.}

